\title{
Menstrual Hygiene: Practice and Challenges among Adolescent Girls of a Private School of Urban Nepal
}

\author{
Neeti Singh ${ }^{1}$, Ang Tshering Sherpa ${ }^{2}$, Srijana Pandey ${ }^{3}$, Amita Pradhan ${ }^{4}$ \\ 1,2Associate Professor, Department of Community Medicine, KIST Medical College and Teaching Hospital, Imadole, \\ Lalitpur, Nepal, ${ }^{3}$ Professor, Department of Community Medicine, KIST Medical College and Teaching Hospital, \\ Imadole, Lalitpur, Nepal, 'Professor, Department of Community Dentistry, Peoples Dental College and Hospital, \\ Kathmandu, Nepal
}

Background: Menstrual health hygiene management (MHM) is the basic right of every female. In developing countries like Nepal, this right is less understood or utilized. Parental and family influences and hence the societal influences plays vital role in behavioral change. In urban sector, the girls studying in the private schools are mostly from privileged background. So there is a need to observethe pattern of practices among private school girls which reflects the scenarios in privileged urban sector. Aims and Objectives: This study is done the practices and challenges for menstrual health hygiene management among adolescent girls of a Private school in Urban Nepal. Material and Methods: A cross sectional study was conducted in a private school selected purposely in the month of April and May 2019. Girls from gradeseven and above were included in the study. Results: All the girls were aware about the process of menstruation. The practices and believes were influenced by their family and facilities provided to them rather knowledge gained at school. All the participantsprefer to use disposal pads and $6.3 \%$ of participants reported that they use both pads and reusable cloths. Most girls did not change the pads at school(56.2\%). All the participants reported that they were hesitant to take help from teachers due to awkwardness. Conclusions: Practices of the individuals is influenced by family beliefs. Again, adolescents spend many hours daily in schools. So strict measures to implement facility in schools for MHMshould be taken.

\section{Website:}

http://nepjol.info/index.php/AJMS

DOI: 10.3126/ajms.v10i4.24432

E-ISSN: 2091-0576

P-ISSN: $2467-9100$

Key words: MHM; Private school; Urban sector

\section{INTRODUCTION}

Menstrual hygiene has been major issues for girls and women of all ages for centuries. There are various beliefs and social taboos related to it, whether it is in rural or urban setup. ${ }^{1-5}$ Even in learned society, age old practices and taboos still exists and practiced widely. ${ }^{6-8}$ This leads to hesitation in discussion and share the problems related to menstruation. Children spend 6 to 7 hours each day in school. It becomes even harder for these teenagers to articulate their need with teachers at school during "The Days". So there is increased chance of absenteeism from school. ${ }^{9,10}$ Adolescence is vulnerable age, both emotionally as well as physically and there is need to understand and provide facilities to these girls without them asking for it. So, this study was conducted to explore the practices and challenges for menstrual health hygiene management among adolescent girls of a private school in urban Nepal.

\section{MATERIALS AND METHODS}

A cross sectional study was done among urban girls studying in a private school. The selection of school was purposely done as it was a new school. Adolescent girls from grades 7 to 10 who gave verbal consent were included in the study. The study was done in the month of April and May 2019. 
A mixed method was used for collection of information. The students were given predesigned and pretested semi structured questionnaire. The questionnaire included various components on menstrual hygiene such as age of menarche, material used, disposal practices both at home and school, facilities provided at school, knowledge regarding menstruation and hygiene.Additionally, qualitative data was collected from respondents $(\mathrm{n}=12)$ who agreed to participate in focusgroup discussion. It was done to understand their in-depth views about menstruation, hygiene, practices and associated taboos and challenges.

Data was entered in Microsoft office Excel for questionnaire and was analyzed in SPSS 21. Data from focus group discussion was entered in Microsoft Word according to the guideline theme. Additionally, the quantitative data was entered in Microsoft Excel and analyzed using the SPSS version 21.0. Qualitative data was analyzed by using thematic analysis. Transcripts were examined line-by-line and coded according to theme. Thematic saturation was considered once the analysis of data offered no new information. The information collected were triangulated and presented in the form of frequencies, percentages and verbatim.

\section{Ethical considerations}

Ethical clearance was taken from the institutional review committee of KIST Medical College and teaching hospital. Permission and consent from the authorized persons was taken from the chosen school. Measures for non disclosure of the information collected were ensured.

\section{RESULTS}

\section{Quantitative result}

The participants from grades seven and above were approached for the study. Among total 35 girl students, 32 participated in the study. Maximum age of the participant was 16 years and the minimum age was 13 years with mean age of 14.59 years $(\mathrm{SD} \pm 1.10)$ (Table 1). The mean age of menarche was 12.37 years $(\mathrm{SD} \pm 0.61)$. All the students reported that they had some knowledge on menstruation. The main source of information was reported as their subject on reproductive health at school.

Among all participants, 28 girls (87.5\%) reported that they were never absent from school due to menstrual cause. However 4 girls (12.5\%) reported of absenteeism. Twenty two participated girls $(66.8 \%)$ seek advices and help from their mothers and 4 girls $(12.5 \%)$ approached both mother and sister. Remaining 6 girls (18.8\%) said they seek advice from their mother and friends.

\section{Qualitative result}

Experience of menstruation hygiene management was explored using qualitative technique. Afocus group discussion was conducted with the guidelines coded into three themes namely: Knowledge on menstruation, Maintenance of Personal hygiene and Challenges and Taboos and Cultural Practices.

\section{Knowledge on menstruation}

All the girls feel uncomfortable to talk about the menstruation with teachers. They reported that the reproductive health was taught by male teacher.The teacher himself was uncomfortable and all of them feel awkward during topic discussion. All the girls said that they were not comfortable with their male counterparts at class so never asked any questions. All the participants reported that they feel more comfortable to discuss queries related to menstruation with family members, preferably to mothers.

"Sir usually does not explain fully about the chapter. He asks us to study in detail by ourselves. I think he himself is uncomfortable to explain.It would have been better if lady teacher teaches us and I am more comfortable to talk about the topic at home, especially with mother." (Grade 7, FID-12)

Maintenance of personal hygiene and challenges All the participants reported that they take help from their mother and sometimes sistersfor buying pads. One girl said that she takes help from her father or brother for buying pads as her mother is homemaker.

"My mother is home maker, so I ask my elder brother and sometimes my father to buy sanitary pads for me." (Grade 9,FID-4)

Two of the girls added that apart from deposable sanitary pads, when at home they use reusable cloths. They wash and dry under sun and reuse again (Table 2).

"At school I use disposal pads, while at home I use reusable clothes... mother says it is traditional way and is good." (Grade8, FID-3)

If the menstruation starts at home, they prepare themselves so that they don't need to change at school. If ever they change at school, they throw in common dustbin which is later collected by municipality. All the participants reported that they were hesitant to talk to their teachers if menstruation starts at school. They either send their friends or they take them along to the teachers to ask for help. They never asked for help from their male teachers. The school provided them with disposable pad when needed.They clean themselves with soap available in toilet (Table 2). 
'Its better we don't change. Don't feel comfortable....we are hesitant that others will come to know,especially boys in class. they may not know as we don't tell....they haven't asked yet. (Grade 8,FID-3)

\section{Taboos and cultural practices}

Most of the participants said that they do not need to restrict themselves during menstruation. All of them were allowed to eat what they like. But majority of them are restricted to enter kitchen. Unanimously all the girls reported that they do not go to religious places and touch things brought or kept for religious purpose. They don't know exactly what happens if they don't follow the practice. They were told by family members that if they don't follow the practice, they will be cursed by god. Two girls reported that they have to wash or clean all the stuffs they used during menstruation. One girl further hesitantly added that she was not allowed to touch tap by her mother. She advises her not to use common toilet.But her grandmother differs in opinion with her mother and allows her to use tap and common toilet.

"I am not allowed to touch taps.If I touch, my mother gets angry. She doesn't allow me to use common bathroom either. She says she also did same from her childhood. If I don't follow the practice, she says... I will be cursed by god. My grandmother is not that strict. She allows me to use tap and toilet secretly. If mother is around, I cannot do."(Grade 9, FID-5)

All the participants agreed that the practice of restrictions don't make them feel good and confident. They don't want others to know when they have menstruation. They agreed that such practices should be abolished and they don't want their children to face the same "shame" as they do.

"We will never ask our children to restrict themselves as we were asked to do. In school we are taught that it is normal physiological process... notbing will bappen to us." (Grade 10, FID-7).

\section{DISCUSSION}

Knowledge and practices regarding menstrual hygiene management has been burning issue in today's world. Although it is considered that girls from urban area are privileged with widened horizon at school premises and households, theyhave to face their own challenges and limitations. In our study, all the girls reported that they had some knowledge on the process of menstruation. The main source of information being their subject taught on reproductive health at school. The qualitative study revealed that the practices they follow were guided by believes and practices of family members, mainly mothers. This result

\begin{tabular}{lcc}
\multicolumn{3}{l}{ Table 1: Characteristics of participants } \\
\hline Characteristics & Frequency & Percentage \\
\hline Grades & 5 & \\
Grade 7 & 9 & 15.6 \\
Grade 8 & 6 & 28.1 \\
Grade 9 & 12 & 18.8 \\
Grade 10 & & 37.5 \\
Ethinicity & 10 & 31.3 \\
Brahmin & 10 & 31.3 \\
Chhettri & 8 & 25.0 \\
Newar & 4 & 12.5 \\
Others & & \\
Material used & 27 & 84.4 \\
Sanitary pad & 5 & 15.6 \\
Both reusable cloth and sanitary & & \\
pad & & \\
Preference & 32 & 100 \\
Use of sanitary pads & &
\end{tabular}

\begin{tabular}{lcc}
\multicolumn{3}{l}{ Table 2: Disposal of used sanitary pads } \\
\hline Characteristics & Frequency & Percentage \\
\hline At school & & \\
Dust bin & 14 & 43.8 \\
Do not change & 18 & 56.3 \\
At home & & \\
Dust bin & 25 & 78.1 \\
Bury & 2 & 6.3 \\
Burn & 5 & 15.6 \\
\hline
\end{tabular}

resonate with other studies done at various places. ${ }^{11-13}$ All the participants preferred using disposable sanitary pads though some girls use cloths as alternative while at home which is mainly guided by family practices and cheap alternative which is similar to other studies. ${ }^{14-16}$ Unhygienic and improper use of cloths as absorbents may lead to high chance of reproductive tract infection. ${ }^{17,18}$ In Urban areas, there is lack of open space which lead to improper drying of the reusable cloths. So there is need to strengthen an advocacy to use the absorbents with right techniques. The target audience should be family members apart from teachers and girls.

Communicating the problem related to menstruation and hygiene management is very tough to many school going girls. In our study it is seen that the girls approach teachers when needed only with the assistance of their girl friends. The qualitative approach in our study revealed that the girls were hesitance to seek for help is due to embarrassment and fear of being teased. This is mainly due to cultural practices and taboos associated with it in our society thus demanding menstruation days to be kept secret. ${ }^{4-7,19,20}$ In our study, only 4 girls participants reported absenteeism from school during menstruation.This may be due to urban location and also the number of participants were less to generalize the outcome. , $^{90,19-21}$ 
Majority of the girls in do not change pads at school $(62.5 \%)$.Girls revealed that it is comfortable for them to change at home. Though, water and soap is provided at school, they still feel discomfort and hesitance. Studies done at various countries reveals that frequent change of absorbents will minimize reproductive tract infection..$^{18}$ In our study, the participants revealed that there was common dustbin for disposal of pads. In Nepal, many organizations are working at rural schools to promote proper disposal of used sanitary pads including use of incineration. ${ }^{10,14,21}$ Our study revealed that though there is knowledge, willing to practice accordingly is fully governed by socio-cultural norms that directly or indirectly affect the success of abolishing scientifically non relevant practices. So, multiple and continuous promotive programs involving both genders should be advocated. However, proper guidelines and monitoring at all schools of any level/sector, whether urban or rural will enhance the essence of the girl's right.

The limitation of our study is that it covers only one private school of urban sector. The numbers of students are small. So, the outcomes from this study may not be generalized with all the schools at urban placement. However, our study used mixed methods to minimized hindrance to explore hidden problems.

\section{CONCLUSION}

This study reveals that family norms, especially mother's views reflect how an adolescent deals with menstruation. At school, girl's confidence to deal with situation seemed to play vital role. This is indirectly related to our socio-cultural and religious believes. Moreover, the type of facilities and environment at school is key factor to utilize the given facility. Though Nepal government promotes distribution of sanitary pads at free of cost at public schools, the assurance of easy access of sanitary pads to every girl can be fulfilled to vast extent by placement of pad dispenser machines or spot at identified private place in all schools. This step will preserve the menstrual hygiene maintenance right of a girl by relieving their hidden stress to "Ask For."

\section{REFERENCES}

1. Kumar A and Srivastava K. Cultural and Social Practices Regarding Menstruation among Adolescent Girls. Social Work in Public Health 2011; 26(6): 594-604.

2. Kumari S. Social, cultural and religious practices during menstruation Jharkhand Journal of Development and Management Studies XISS 2017; 15(3): 7451-7459.

3. Parajuli P, Paudel N and Shrestha S. Knowledge and Practices Regarding Menstrual Hygiene among Adolescent Girls of Rural Nepal. Journal of Kathmandu Medical College 2017; 5(1): 23-27.

4. Kamaljit K, Arora B, Singh GK and Neki NS. Social Beliefs and
Practices associated with Menstrual Hygiene among Adolescent Girls of Amritsar, Punjab, India. JIMSA 2012; 25 (2):69-70.

5. Mohamed Y, Durrant K, Huggett C, Davis J, Macintyre A, Menu S, et al. Qualitative exploration of menstruation-related restrictive practices in Fiji, Solomon Islands and Papua New Guinea. Plos Medicine 2018.

6. Patle R and Kubde S. Comparative study on menstrual hygiene in rural and urban adolescent. International Journal of Medical Science and Public Health 2014; 3 (2):129-132.

7. Shakya D. Menstrual Hygiene and Health: Knowledge, Practice and Aspirations among Adolescent Girls of Kathmandu Valley. [Online]. 2017 Mar 24[Cited 2018 Dec].

8. Sharma P, Singh N, Tempe A and Sharma S. Knowledge, practices and restrictions related to menstruation in young girls: a study from North India International Journal of Community Medicine and Public Health. Int J Community Med Public Health 2018; 5(8):3340-3344.

9. Egegne TK and Sisay MM. Menstrual hygiene management and school absenteeism among female adolescent students in northeast Ethiopia. BMC Public Health 2014; 14:1118.

10. Analysis of menstrual hygiene practices in Nepal.The Role of WASH in Schools Programme for Girls Education. [Online]. 2016. [Cited 2019 Jan].

11. Mouli VC and Patel SP. Mapping the knowledge and understanding of menarche, menstrual hygiene and menstrual health among adolescent girls in low- and middle-income countries. Reproductive Health 2017 Mar; 14: 30

12. Sooki Z, Shariati M, Chaman R, Khosravi A, Effatpanah $M$ and Keramat A. Role of Mother in Informing Girls about Puberty: A Meta-Analysis Study. Nurs Midwifery Stud 2016 Mar;5(1).

13. Murye AF and Mamba SR. Practices of Managing Menstrual Hygiene by Girls in Public Boarding Secondary Schools - The Case of the Hhohho Region of Swaziland. Health Sci J 2017; 11(6): 534.

14. Kamath R, Ghosh D and Chandrasekaran V. A study on knowledge and practices regarding menstrual hygiene among rural and urban adolescent girls in UdupiTaluk, Manipal, India. Global journal of medicine and public health 2013. 2(4).

15. Menstrual Hygiene Management in Schools in South Asia: Nepal Country Snapshotreportfrom UN Children's Fund. Water Aid 2018 May.

16. Francis A and Sambulo M. Revelation Mamba Practices of Managing Menstrual Hygiene by Girls in Public Boarding Secondary Schools - The Case of the Hhohho Region of Swaziland. Health Sci J 2017; 11(6): 534.

17. Das P, Baker KK, Dutta A, Swain T, Sahoo S, Das BS, et al. Menstrual Hygiene Practices, WASH Access and the Risk of Urogenital Infection in Women from Odisha, India. PLoS One. 2015; 10(6): e0130777.

18. Torondel B, Sinha S, Mohanty JR, Swain T, Sahoo P, Panda B, et al. Association between unhygienic menstrual management practices and prevalence of lower reproductive tract infections: a hospital-based cross-sectional study in Odisha, India.BMC Infect Dis 2018;18(1):473.

19. Rajagopal $S$ and Mathur K. Breaking the silence around menstruation': experiences of adolescent girls in an urban setting in India. Gender \& Development 2017; 25(2):303-317.

20. Kaur R, Kaur K and Kaur R. Menstrual Hygiene, Management, and Waste Disposal: Practices and Challenges Faced by Girls/ Women of Developing Countries. Journal of Environmental and Public Health 2018.

21. Menstrual hygiene in South Asia. A neglected issue for WASH (water, sanitation and hygiene) programmes. Water Aid [Online]. 2010 [cited 2 may 2019]. 
Authors Contribution:

NS- Designing, Data collection,analysis and write upof the manuscript; ATS- Designing, Data collection and analysis of the manuscript; SP- Data collectionand write up of the manuscript; AP- Designing and Data analysis and write up of the manuscripts.

Work attributed to:

Department of Community Medicine, KIST Medical College and Teaching Hospital, Imadole, Lalitpur, Nepal.

Orcid ID:

Dr. Neeti Singh - (i) https://orcid.org/0000-0002-4023-072X

Dr. Ang Tshering Sherpa - (D) https://orcid.org/0000-0001-5078-6505

Dr. Srijana Pandey - (1) https://orcid.org/0000-0003-0142-4326

Dr. Amita Pradhan - (10) https://orcid.org/0000-0003-0363-8627

Source of Support: Nil, Conflict of Interest: None declared. 